\title{
Market And Welfare Effects Of Multi-Product Mergers With Reference To Tyson-IBP Merger
}

David Bouras, Lincoln University, USA

Azzeddine Azzam, University of Nebraska-Lincoln, USA

\begin{abstract}
In this paper, we provide a conceptual framework for analyzing the market and welfare effects of mergers that result in multiproduct firms producing strongly demand-related products and derive the conditions under which such type of mergers improve welfare. The Tyson-IBP merger is used as an empirical application of the model. Using estimates of own- and cross-price elasticities of demand for beef, pork, and chicken, we infer that the Tyson-IBP merger has generated the costefficiencies necessary to make consumers and livestock producers better off.
\end{abstract}

Keywords: Mergers; Multi-Product Firms; Welfare Effect; Market Effect; Cost-Efficiencies

\section{INTRODUCTION}

e n 2001, Tyson Foods, the world largest chicken processor, merged with IBP, the leading beef processor and the second largest pork processor; resulting in a new company that ranks first in beef, with 27 percent market share; first in chicken, with 23 percent market share; and second in pork, with a market share of 18 percent. Approval of the merger by the Justice department prompted Senator Chuck Grassley (R-IA) to reintroduce the Agricultural Competition Enhancement Act with a provision to review the merger approval process. In the Senator's view - one widely shared by livestock groups at the time - was that "the combination of the nation's largest poultry producer with the world's largest producer of beef and pork products would result in significantly reduced market opportunities, as well as increase the possibility of anti-competitive business practices....[The] combined IBP-Tyson presence in the retail market would negatively affect product choice and the prices consumers pay at the meat counter" (Press Release, 2001).

The merger has now been in place for over a decade and, to the authors' knowledge, with the exception of a few general remarks to the press (e.g., McInnis, 2001) and a descriptive essay (Wards and Meyers, 2001) at the inception of the merger, economists have been silent on the market and welfare effects of the Tyson-IBP merger. This is a void because what distinguishes the merger from other horizontal mergers in the meat industry is that, in addition to producing the beef and pork previously produced jointly by IBP, Tyson also produces chicken, which substitutes strongly for beef and pork in consumer demand. In that setting, the welfare effects of the merger on the marketing chain are determined by equilibrium outputs and prices that are conditioned not only on the own- and cross-price elasticities of demand of each product, but also on the merged firm's multiproduct cost structure, and both own- and cross-market responses to variations in its own outputs and prices.

In this article, we 1) provide a general conceptual framework for analyzing the market and welfare effects of mergers that result in firms producing strongly demand-related products jointly, 2) derive the condition under which such mergers improve social welfare in the marketing channel, and 3) compute a measure for that condition for the beef, pork, and poultry marketing channels using available empirical estimates of own- and cross-elasticities of demand for the three meats.

In terms of its relation to the merger literature, this paper falls between studies focusing on mergers between Cournot firms producing the same homogeneous products (Salant, Switzer and Reynolds, 1983; Perry and 
Porter, 1985; Farrell and Shapiro, 1990) and mergers between Bertrand firms producing differentiated products (McElroy, 1993; Deneckree and Davidson, 1985). In the first instance, the approach would be applicable in the food industry to mergers between beef packers, for example. Though beef would be demand-related to pork and chicken, only the own-price elasticities enter the profit-maximizing calculus of the beef-producing firms. In the second instance, the approach would be applicable to mergers of firms that produce, say, ready-to-eat cereals. In this case, both own- and cross-price elasticities enter the supply relation of the merged firm. In our case, the own- and crosselasticities are key to the analysis, but beef, pork and chicken obviously do not represent variations within a product class as do breakfast cereals.

The work most closely related to ours is by Vannoni (2004). He developed a multiproduct monopoly model to rationalize the three major views in literature on corporate diversification (the resource efficiency view, the managerial or agency view, and market power view) resulting either from mergers between single-product monopolists or the introduction of new goods by a single-product monopoly. Vannoni shows that corporate diversification depends on the interplay between scope economies from joint production, strategic interactions between firms, demand-relatedness, and multi-market contact.

The starting point of our work is a stylized model of two single-product industries, each initially consisting of a Cournot duopoly/duopsony. Each product is homogenous and substitutes for the other. A merger takes place between a firm in industry 1 and a firm in industry 2 . The merged firms maximize joint profits and compete with the rest of non-merged firms a la Cournot. The effects of the merger on consumers, farmers, merged and non-merged firms are examined by comparing their respective pre-merger and post-merger surpluses. The direction of change in social welfare is determined by the interplay between scope economies and demand-relatedness. Using published beef, pork, and chicken elasticity estimates to quantify the condition under which a multi-product merger improves social welfare, we find that it would be implausible for a Tyson-IBP type merger not to satisfy that condition.

\section{CONCEPTUAL FRAMEWORK}

Consider two food processing industries, each consisting of a Cournot duopoly/duopsony. Firms in the first industry produce a homogeneous product - call it product 1 - where one unit of farm input is converted into one unit of final consumer food product. Denote industry output of product 1 by $\mathrm{Q}_{1}$. Firms in the second industry produce product 2, also homogenous and requires one unit of farm input. Industry output of product 2 is $\mathrm{Q}_{2}$. The two products, $\mathrm{Q}_{1}$ and $\mathrm{Q}_{2}$, are demand-related with inverse demands:

$\mathrm{P}_{1}=\alpha-2 \mathrm{Q}_{1}-\sigma \mathrm{Q}_{2}$

$P_{2}=\alpha-2 Q_{2}-\sigma Q_{1}$

where $\alpha>0$ and $\sigma \in[0,2]$ measures the degree of substitutability between the two products. ${ }^{1}$ The products are independent when $\sigma=0$ and perfect substitutes when $\sigma=2$.

We consider a merger between a firm in industry 1 and a firm in industry 2 . The merged entity becomes a two-product firm in competition with two single-product firms, one in industry 1 and one in industry 2 . The effects of the merger on consumers, farmers, and processors are determined by comparing the price, quantity, and welfare measures from the pre-merger equilibrium to those of the post-merger equilibrium.

\footnotetext{
${ }^{1}$ The inverse demands are derived from maximizing the quadratic utility function: $\mathrm{U}\left(\mathrm{Q}_{1}, \mathrm{Q}_{2}\right)=\alpha\left(\mathrm{Q}_{1}+\mathrm{Q}_{2}\right)-\left(\mathrm{Q}_{1}^{2}+\mathrm{Q}_{2}^{2}\right)-\sigma \mathrm{Q}_{1} \mathrm{Q}_{2}+\mathrm{m}$, where $\mathrm{m}=\mathrm{Y}-\sum_{\mathrm{i}=1}^{2} \mathrm{p}_{\mathrm{i}} \mathrm{Q}_{\mathrm{i}}$ is the portion of the income spent on other goods (Shaked and Sutton, 1990; Symeonidis, 2002).
} 


\section{Pre-Merger Equilibrium}

Before the merger, the $\mathrm{j}^{\text {th }}$ firm, for $\mathrm{j}=1,2$, in industry 1 supplies product 1 by maximizing profits:

$\underset{\mathrm{q}_{1}}{\operatorname{Max}} \pi_{1}^{\mathrm{j}}=\left(\mathrm{P}_{1}-\mathrm{c}_{1}-\mathrm{w}_{1}\right) \mathrm{q}_{1}^{\mathrm{j}}$,

where $\mathrm{q}_{1}$ is output, $\mathrm{c}_{1}$ is marginal processing cost, and $\mathrm{w}_{1}$ is price of the farm input used in the production of good 1 . The supply schedule for the farm input takes the form:

$\mathrm{w}_{1}\left(\mathrm{Q}_{1}\right)=\mathrm{b}_{1} \mathrm{Q}_{1}$,

where $b_{1}>0$ and $\left(q_{1}^{1}+q_{1}^{2}\right)=Q_{1}$

Differentiating (3) with respect to $q_{1}^{j}$, for $\mathrm{j}=1,2$, substituting for $\mathrm{P}_{1}$ from (1) and $\mathrm{w}_{1}$ from (4) in the firstorder-conditions (FOC), and rearranging yields:

$2\left(2+b_{1}\right) q_{1}^{1}+\left(2+b_{1}\right) q_{1}^{2}+\sigma q_{2}^{1}+\sigma q_{2}^{2}=\left(\alpha-c_{1}\right)$

for firm 1 and

$$
\left(2+b_{1}\right) q_{1}^{1}+2\left(2+b_{1}\right) q_{1}^{2}+\sigma q_{2}^{1}+\sigma q_{2}^{2}=\left(\alpha-c_{1}\right)
$$

for firm 2 .

In industry 2 , the $\mathrm{j}^{\text {th }}$ firm's maximization problem, also for $\mathrm{j}=1,2$; is:

$$
\underset{\mathrm{q}_{2}^{1}}{\operatorname{Max}} \pi_{2}^{\mathrm{j}}=\left(\mathrm{P}_{2}-\mathrm{c}_{2}-\mathrm{w}_{2}\right) \mathrm{q}_{2}^{\mathrm{j}}
$$

where $\mathrm{q}_{2}$ is output, $\mathrm{c}_{2}$ is marginal processing cost, and $\mathrm{w}_{2}$ is the price of the farm input used in the production of good 2. Supply of farm input 2 is given by:

$\mathrm{w}_{2}\left(\mathrm{Q}_{2}\right)=\mathrm{b}_{2} \mathrm{Q}_{2}$

where $\mathrm{b}_{2}>0$ and $\left(\mathrm{q}_{2}^{1}+\mathrm{q}_{2}^{2}\right)=\mathrm{Q}_{2}$.

Maximizing (7) with respect to $q_{2}^{j}$, for $j=1,2$, substituting for $P_{2}$ and $w_{2}$ using (2) and (8) in the FOC, and rearranging yields:

$\sigma q_{1}^{1}+\sigma q_{1}^{2}+2\left(2+b_{2}\right) q_{2}^{1}+\left(2+b_{2}\right) q_{2}^{2}=\left(\alpha-c_{2}\right)$

for firm 1 and 
$\sigma \mathrm{q}_{1}^{1}+\sigma \mathrm{q}_{1}^{2}+\left(2+\mathrm{b}_{2}\right) \mathrm{q}_{2}^{1}+2\left(2+\mathrm{b}_{2}\right) \mathrm{q}_{2}^{2}=\left(\alpha-\mathrm{c}_{2}\right)$

for firm 2 .

Pre-merger equilibrium prices and quantities require simultaneous solution of (5), (6), (9), and (10). For tractability, we economize on notation by setting $\mathrm{c}_{1}=\mathrm{c}_{2}=1 / 2$ and all parameters other than $\sigma$ equal to one. As will become clear when we discuss the post-merger equilibrium, $\sigma$ is one of two parameters crucial in determining the market and welfare effects of mergers. The other parameter is the one capturing scope economies (or diseconomies) from a merger between multiproduct firms. Table 1 contains pre-merger equilibrium prices, quantities, and welfare measures.

Table 1: Pre-Merger Equilibrium Prices, Quantities, and Welfare

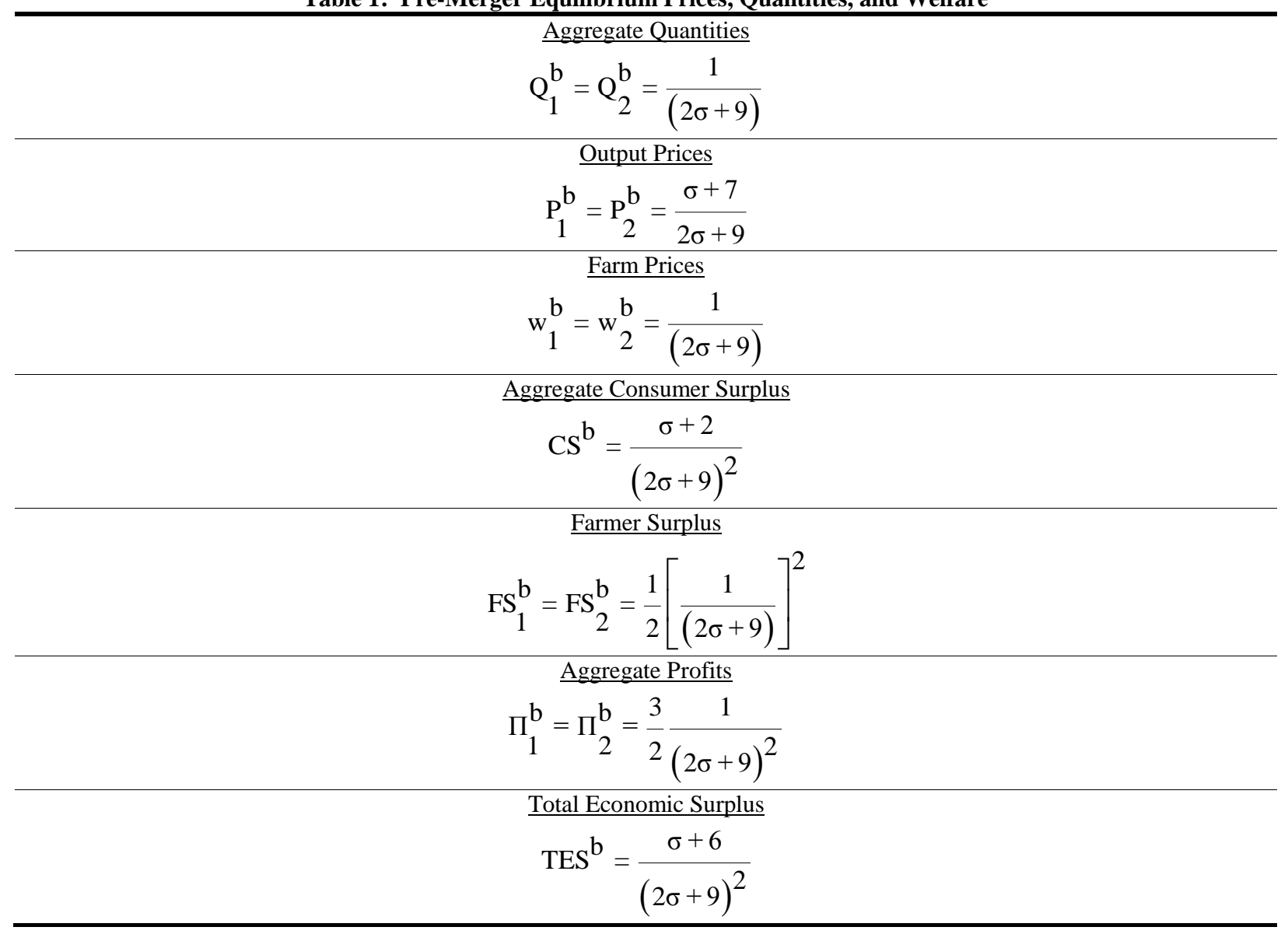

\section{Post-Merger Equilibrium}

Firm 1 in industry 1 merges with firm 2 in industry 2 to form a two-product firm. The two products are produced jointly with costs:

$\mathrm{C}\left(\mathrm{q}_{1}^{1}, \mathrm{q}_{2}^{2}\right)=\mathrm{c}_{1} \mathrm{q}_{1}^{1}+\mathrm{c}_{2} \mathrm{q}_{2}^{2}-\mathrm{sq}_{1} \mathrm{q}_{2}^{2}$, 
where $s$ is a cost parameter reflecting (dis)economies of scope if it is positive (negative) (Cabral and Villas-Boas, 2001). ${ }^{2}$ The decision problem for the two-product firm is to:

$$
\underset{\mathrm{q}_{1}^{1}, \mathrm{q}_{2}^{2}}{\operatorname{Max}} \pi^{\mathrm{m}}=\underset{\mathrm{q}_{1}^{1}, \mathrm{q}_{2}^{2}}{\operatorname{Max}}\left[\left(\mathrm{P}_{1}-\mathrm{c}_{1}-\mathrm{w}_{1}\right) \mathrm{q}_{1}^{1}+\left(\mathrm{P}_{2}-\mathrm{c}_{2}-\mathrm{w}_{2}\right) \mathrm{q}_{2}^{2}+\mathrm{sq}_{1}^{1} \mathrm{q}_{2}^{2}\right]
$$

with respect to $q_{1}^{1}$ and $q_{2}^{2}$. Substituting equations (1), (2), (4) and (8) into the relevant FOC and rearranging, yields the expression:

$$
2\left(2+b_{1}\right) q_{1}^{1}+\left(2+b_{1}\right) q_{1}^{2}+\sigma q_{2}^{1}+(2 \sigma-s) q_{2}^{2}=\left(\alpha-c_{1}\right)
$$

for product 1 and

$$
(2 \sigma-s) q_{1}^{1}+\sigma q_{1}^{2}+\left(2+b_{2}\right) q_{2}^{1}+2\left(2+b_{2}\right) q_{2}^{2}=\left(\alpha-c_{2}\right)
$$

for product 2 .

The other firms not involved in the merger still have the same FOCs as in the pre-merger situation (equation 6 and 9). Post-merger equilibrium prices and quantities are obtained by solving (6), (9), (13), and (14) simultaneously. Resulting prices, quantities, and welfare measures are shown in Table 2.

Table 2: Post-Merger Equilibrium Prices, Quantities, and Welfare

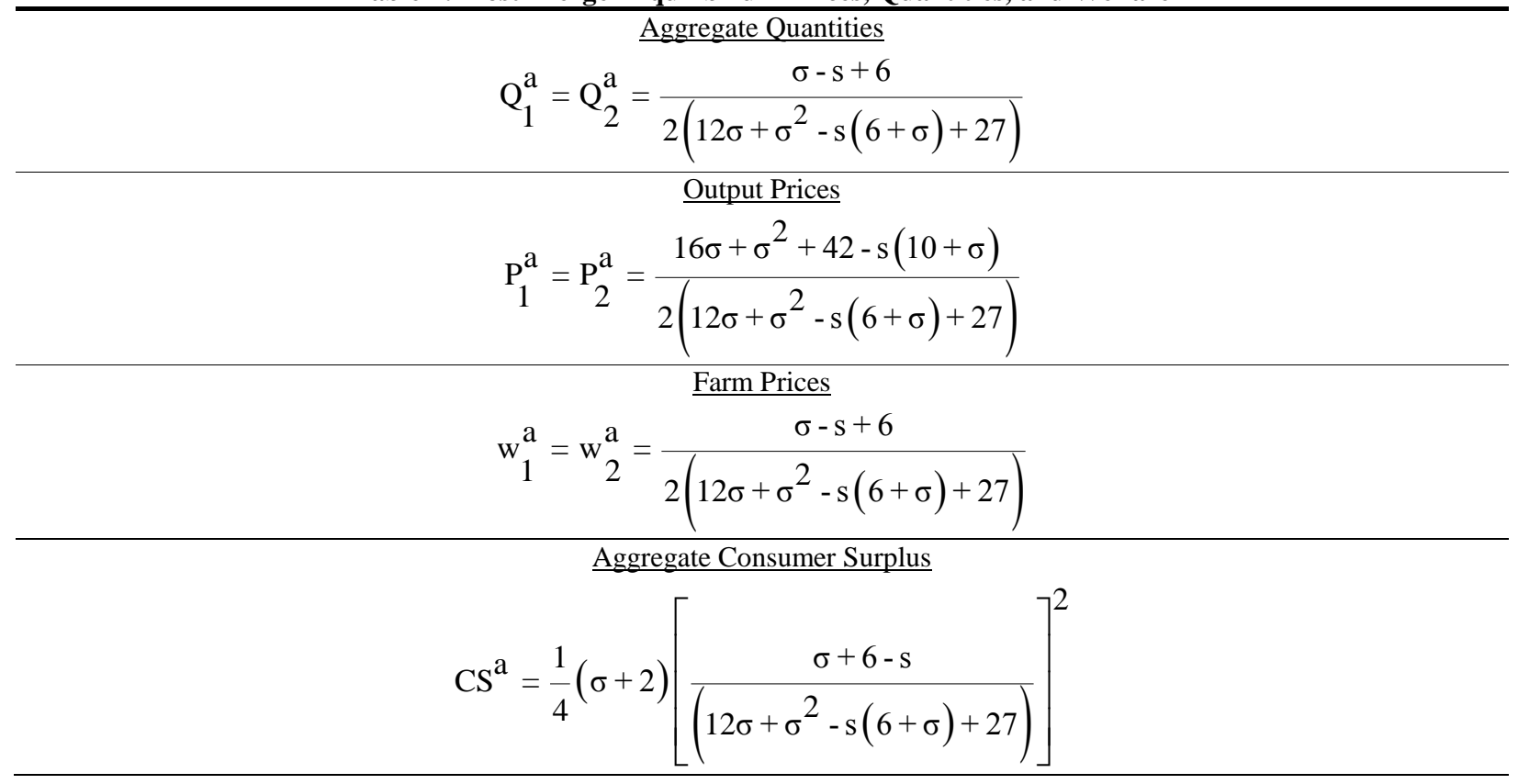

${ }^{2}$ To guarantee non-negative quantities, the cost parameter, $s$, should be restricted to $s \in(\infty-, \sigma+3]$. This restriction ensures, at the same time, non-negative marginal costs (Appendix A). 
Table 2 cont.

Framer Surplus

$$
\begin{gathered}
\mathrm{FS}_{1}^{\mathrm{a}}=\mathrm{FS}_{2}^{\mathrm{a}}=\frac{1}{8}\left[\frac{\sigma+6-\mathrm{s}}{\left(12 \sigma+\sigma^{2}-\mathrm{s}(6+\sigma)+27\right)}\right]^{2} \\
\mathrm{TSW}^{\mathrm{a}}=\frac{1}{4} \frac{\Pi_{1}^{\mathrm{a}}=\Pi_{2}^{\mathrm{a}}=\frac{3}{8} \frac{\left(126 \sigma-81 \mathrm{~s}-30 \mathrm{~s} \sigma+9 \mathrm{~s}^{2}+21 \sigma^{2}+\sigma^{3}-2 \mathrm{~s} \sigma^{2}+\mathrm{s}^{2} \sigma+216\right)}{\left(18 \sigma+2 \mathrm{~s}^{2}-\mathrm{s}(15+4 \sigma)\right)}}{\frac{\text { Total Economic Surplus }}{\left(12 \sigma+\sigma^{2}-\mathrm{s}(6+\sigma)+27\right)^{2}}}
\end{gathered}
$$

\section{MARKET AND WELFARE EFFECTS OF THE MERGER}

We measure price, quantity, and welfare effects of the merger by the difference between the post- and premerger equilibrium prices, quantities, and welfare measures reported in Tables 1 and 2, respectively.

\section{Price and Quantity Effects}

The respective changes in retail prices, farm prices, and market quantities are given by:

$$
\begin{aligned}
& \Delta \mathrm{P}_{\mathrm{i}}=\left(\mathrm{P}_{\mathrm{i}}^{\mathrm{a}}-\mathrm{P}_{\mathrm{i}}^{\mathrm{b}}\right) \Rightarrow \Delta \mathrm{P}_{\mathrm{i}}=\frac{3}{2} \frac{(\sigma-\mathrm{s})(\sigma+2)}{\left[\left(12 \sigma+\sigma^{2}+27-\mathrm{s}(6+\sigma)\right)(2 \sigma+9)\right]}, \\
& \Delta \mathrm{w}_{\mathrm{i}}=\left(\mathrm{w}_{\mathrm{i}}^{\mathrm{a}}-\mathrm{w}_{\mathrm{i}}^{\mathrm{b}}\right) \Rightarrow \Delta \mathrm{w}_{\mathrm{i}}=\frac{3}{2} \frac{(\mathrm{s}-\sigma)}{\left[\left(12 \sigma+\sigma^{2}+27-\mathrm{s}(6+\sigma)\right)(2 \sigma+9)\right]},
\end{aligned}
$$

and

$$
\Delta Q_{i}=\left(Q_{i}^{a}-Q_{i}^{b}\right) \Rightarrow \Delta Q_{i}=\frac{3}{2} \frac{(s-\sigma)}{\left[\left(12 \sigma+\sigma^{2}+27-s(6+\sigma)\right)(2 \sigma+9)\right]}
$$

Since the denominator in the last three expressions is positive (Appendix B.1), it follows that when $s>\sigma$, consumer prices decline, farm prices rise, and quantities rise. The reverse holds when $\mathrm{s}<\sigma$.

The preceding results lead to the following proposition:

Proposition 1: If the cost effect, as captured by the cost parameter, $s$, dominates the substitutability effect, as given by $\sigma$, then the merger results in an increase in market quantities and farm prices and a decrease in output prices. The reverse holds if the substitutability effect dominates the cost effect or in the presence of diseconomies of scope. 
If these two effects cancel each other out, then the merger has a neutral effect on aggregate quantities and farm and output prices.

\section{Consumer and Farmer Surplus Effects}

The respective changes in consumer and farmer surplus are given by:

$$
\Delta \mathrm{CS}=\left(\mathrm{CS}^{\mathrm{a}}-\mathrm{CS}^{\mathrm{b}}\right) \Rightarrow \Delta \mathrm{CS}=\frac{3(s-\sigma)(\sigma+2)}{4} \frac{\left[108+4 \sigma^{2}+45 \sigma-s(21+4 \sigma)\right]}{\left[\left(12 \sigma+\sigma^{2}-6 s-s \sigma+27\right)(2 \sigma+9)\right]^{2}}
$$

and

$$
\Delta \mathrm{FS}_{\mathrm{i}}=\left(\mathrm{FS}_{\mathrm{i}}^{\mathrm{a}}-\mathrm{FS}_{\mathrm{i}}^{\mathrm{b}}\right) \Rightarrow \Delta \mathrm{FS} \mathrm{i}_{\mathrm{i}}=\frac{3(\mathrm{~s}-\sigma)}{8} \frac{\left[108+4 \sigma^{2}+45 \sigma-\mathrm{s}(21+4 \sigma)\right]}{\left[\left(12 \sigma+\sigma^{2}+27-\mathrm{s}(6+\sigma)\right)(2 \sigma+9)\right]^{2}} .
$$

Since $\left[\left(45 \sigma+4 \sigma^{2}+108\right)-\mathrm{s}(21+4 \sigma)\right]>0$ (Appendix B.2), both consumers and farmers are better off when $\mathrm{s}>\sigma$. The opposite follows.

The preceding welfare results can be summarized in the following proposition:

Proposition 2: If the merger generates efficiency gains that are larger than the substitutability effect, then farmers and consumer surpluses increase following the merger. The reverse holds if the substitutability effect is larger than the cost effect or in the presence of diseconomies of scope.

\section{Effect on Firm Performance}

Non-Merged Firms

To evaluate the effect of the merger on the performance of the non-merged firms, we compare their combined pre-merger profits to their post-merger combined profit. Let $\Pi^{\text {na }}$ and $\Pi^{\text {nb }}$ be their combined post and pre-merger profits, respectively. The change in profits for non-merged firms is:

$$
\Delta \Pi^{\mathrm{n}}=\left(\Pi^{\mathrm{na}}-\Pi^{\mathrm{nb}}\right)=\frac{3(\sigma-\mathrm{s})(\sigma+3)}{4} \frac{\left[18+9 \sigma+\sigma^{2}-\mathrm{s}(\sigma+5)\right]}{\left[\left(12 \sigma+\sigma^{2}-6 \mathrm{~s}-\mathrm{s} \sigma+27\right)(2 \sigma+9)\right]^{2}} .
$$

Since the numerator $\left[18+9 \sigma+\sigma^{2}-\mathrm{s}(\sigma+5)\right]>0$ (Appendix B.3), it follows that $\Delta \Pi^{\mathrm{n}}<0$ whenever $s>\sigma$.

Merged Firms

Let $\Pi^{\mathrm{mb}}$ and $\Pi^{\mathrm{ma}}$ be merged firms' respective pre-merger combined profits and post-merger joint-profit, respectively. The change in profits for merged firms is: 
$\Delta \Pi^{\mathrm{m}}=\left(\Pi^{\mathrm{ma}}-\Pi^{\mathrm{mb}}\right)=\frac{3}{4} \frac{\Phi}{\left[\left(12 \sigma+\sigma^{2}-6 \mathrm{~s}-\mathrm{s} \sigma+27\right)(2 \sigma+9)\right]^{2}}$,

where, $\Phi=\left(\begin{array}{l}405 s+288 s \sigma+60 s \sigma^{2}+4 s \sigma^{3}-162 \sigma-72 s^{2}-24 s^{2} \sigma \\ -108 \sigma^{2}-24 \sigma^{3}-2 \sigma^{4}-2 s^{2} \sigma^{2}>0\end{array}\right)$,

which is unambiguously positive for $s>\sigma$ (Appendix B.4).

This leads to the following proposition:

Proposition 3: If the cost effect is larger than the degree of substitutability, then the merger is profitable for the merged firms but unprofitable for the non-merged firms. The reverse holds in the presence of diseconomies of scope. If the cost effect is lower than the degree of substitutability and economies of scope are present, then the merger has a positive effect on the non-merged firms. This holds also for the merged entities but only for certain combinations of $\sigma$ and $s$.

The intuition behind Proposition 3 is that in the presence of diseconomies of scope $(s<0)$, the non-merged firms have a cost advantage over the merged entity and, as a result, produce more and earn higher profits. Conversely, if the merger generates cost efficiencies that are larger than the substitutability effect $(s>\sigma)$, this leads to a reduction in non-merged firms' profits. Therefore, non-merged parties are worse off.

Regarding the merged entity in the presence of economies of scope, it faces a trade-off between costsavings and substitutability effect. While the former has a positive effect on profits, the latter has a negative effect. Thus, the effect of the merger on the profits of the merged entity is higher when products are independent and cost savings are larger. When the degree of substitutability becomes larger, coupled with diseconomies of scope $(s<0)$, the merged parties' profit decreases and hence the merger is disadvantageous for the merging parties. It follows that the presence of economies of scope is a necessary, but not a sufficient condition, for this type of a merger to be profitable.

\section{Total Economic Surplus}

Let $T E S^{a}$ and $T E S^{b}$ be post and pre-merger social surplus, respectively. The change in social surplus is:

$\Delta \mathrm{TES}=\left(\mathrm{TES}^{\mathrm{a}}-\mathrm{TES}^{\mathrm{b}}\right) \Rightarrow \Delta \mathrm{TES}=\frac{9(3 \sigma+9-\mathrm{s})\left(15 \mathrm{~s}-6 \sigma+3 \mathrm{~s} \sigma-\sigma^{2}\right)}{4\left[\left(12 \sigma+\sigma^{2}-\mathrm{s}(6+\sigma)+27\right)(2 \sigma+9)\right]^{2}}$,

which can be shown to be positive when $\mathrm{s}>\frac{\sigma(\sigma+6)}{3(\sigma+5)}$ (Appendix 1.5). This leads to our fourth proposition:

Proposition 4: The merger is welfare enhancing (reducing) provided that $\mathrm{s}>\frac{\sigma(\sigma+6)}{3(\sigma+5)}\left(\mathrm{s}<\frac{\sigma(\sigma+6)}{3(\sigma+5)}\right)$. The merger has a neutral effect on welfare if products are independent and cost-savings are ruled out (i.e., $\sigma=s=0)$. 


\section{MODEL APPLICATION}

To exactly find out which of the relationships between $\sigma$ and $s$ holds, as suggested by the four propositions, one needs information on both parameters. Since neither is available, we focus our attention on computing $\sigma$ because, as we demonstrate below, it can be approximated from available estimates of own- and cross-price elasticities. The computed $\sigma$ provides a threshold of the cost-efficiencies necessary to improve social welfare. However, since the $\sigma$ in the stylized model is for a two-good case, while the Tyson-IBP merger involves three goods, we devise a procedure that embeds available empirical estimates of own- and cross-elasticities of beef, pork, and chicken in the inverse demand function (1 and 2) and solve for $\sigma$.

The starting point of the procedure is to assume equation (1) represents inverse demand for chicken $\left(\mathrm{q}_{\mathrm{c}}\right)$ and equation (2) represents inverse demand for a composite good aggregating beef and pork $\left(\mathrm{q}_{\mathrm{m}}\right)$. The revised demands are rewritten as:

$$
\begin{aligned}
& P_{c}=1-2 q_{c}-\sigma q_{m} \\
& P_{m}=1-2 q_{m}-\sigma q_{c}
\end{aligned}
$$

Next, convert the two prices and quantities into logs and take the total differential to obtain:

$$
\begin{aligned}
& d \ln p_{c}=-2 d \ln q_{c}-\sigma d \ln q_{m} \\
& d \ln p_{m}=-2 d \ln q_{m}-\sigma d \ln q_{c}
\end{aligned}
$$

Solving simultaneously for $\mathrm{dln}_{\mathrm{c}}$ and $\mathrm{dln} \mathrm{q}_{\mathrm{m}}$ yields:

$$
\mathrm{dlnq}_{\mathrm{c}}=\frac{\sigma \mathrm{d} \ln \mathrm{p}_{\mathrm{m}}-2 \mathrm{dln} \mathrm{p}_{\mathrm{c}}}{\left(4-\sigma^{2}\right)}
$$

and

$$
d \ln q_{m}=\frac{\sigma d \ln p_{c}-2 d \ln p_{m}}{\left(4-\sigma^{2}\right)}
$$

$$
\text { Multiplying through (17) by }\left(\frac{4-\sigma^{2}}{d \ln q_{c}}\right) \text { gives: }
$$

$$
\left(4-\sigma^{2}\right)=\sigma\left[\frac{d \ln p_{m}}{d \ln q_{c}}\right]-2\left[\frac{d \ln p_{c}}{d \ln q_{c}}\right] \Rightarrow>\left(4-\sigma^{2}\right)=\left(\frac{\sigma}{\eta_{c m}}-\frac{2}{\eta_{c c}}\right),
$$

where $\eta_{\mathrm{cm}}=\left[\frac{d \ln \mathrm{q}_{\mathrm{c}}}{d \ln \mathrm{p}_{\mathrm{m}}}\right]$ is the elasticity of chicken with respect to the price of the composite good (beef and pork) and $\eta_{\mathrm{cc}}=\left[\frac{\mathrm{dlnq_{c }}}{\operatorname{dln} p_{c}}\right]$ is the own-price elasticity of chicken. 


$$
\begin{aligned}
& \text { Multiplying through (18) by }\left(\frac{4-\sigma^{2}}{d \ln q_{m}}\right) \text { yields: } \\
& \left(4-\sigma^{2}\right)=\sigma\left[\frac{d \ln p_{c}}{d \operatorname{lnq} q_{m}}\right]-2\left[\frac{d \ln p_{m}}{d \ln q_{m}}\right]=>\left(4-\sigma^{2}\right)=\left(\frac{\sigma}{\eta_{m c}}-\frac{2}{\eta_{m m}}\right) \\
& \text { where } \eta_{m c}=\left[\frac{d \operatorname{lnq}}{d \ln p_{c}}\right] \text { is the price elasticity of the composite good with respect to the price of chicken and } \\
& \eta_{\mathrm{mm}}=\left[\frac{d \operatorname{lng} q_{m}}{d \ln p_{m}}\right] \text { is the own-price elasticity of the composite good. }
\end{aligned}
$$

From (19) and (20), it follows that:

$\left(\frac{\sigma}{\eta_{\mathrm{mc}}}-\frac{2}{\eta_{\mathrm{mm}}}\right)=\left(\frac{\sigma}{\eta_{\mathrm{cm}}}-\frac{2}{\eta_{\mathrm{cc}}}\right)$

Equation (21) implies:

$$
\sigma=2\left[\frac{\frac{1}{\eta_{\mathrm{mm}}}-\frac{1}{\eta_{\mathrm{cc}}}}{\frac{1}{\eta_{\mathrm{mc}}}-\frac{1}{\eta_{\mathrm{cm}}}}\right]
$$

Assume the composite good takes the form:

$$
q_{m}=q_{b}\left(P_{b}, P_{p}, P_{c}\right)+q_{p}\left(P_{b}, P_{p}, P_{c}\right)
$$

where $\mathrm{q}_{\mathrm{b}}$ and $\mathrm{q}_{\mathrm{p}}$ are the respective quantities of beef and pork and $\mathrm{P}_{\mathrm{b}}, \mathrm{P}_{\mathrm{c}}$ and $\mathrm{P}_{\mathrm{p}}$ are the respective prices of beef, chicken, and pork. Differentiating (23) with respect to $\mathrm{P}_{\mathrm{m}}, \mathrm{P}_{\mathrm{c}}$ yields the expression for $\eta_{\mathrm{mm}}$ and $\eta_{\mathrm{mc}}$ in terms of own and cross-elasticities for the three meats.

$$
\begin{aligned}
& \eta_{\mathrm{mm}}=\mathrm{S}_{\mathrm{b}}\left(\eta_{\mathrm{bb}} \varepsilon_{\mathrm{bm}}+\eta_{\mathrm{bp}} \varepsilon_{\mathrm{pm}}+\eta_{\mathrm{bc}} \varepsilon_{\mathrm{cm}}\right)+\mathrm{S}_{\mathrm{P}}\left(\eta_{\mathrm{pb}} \varepsilon_{\mathrm{bm}}+\eta_{\mathrm{pp}} \varepsilon_{\mathrm{pm}}+\eta_{\mathrm{pc}} \varepsilon_{\mathrm{cm}}\right) \\
& \eta_{\mathrm{mc}}=\mathrm{S}_{\mathrm{b}}\left(\eta_{\mathrm{bb}} \varepsilon_{\mathrm{bc}}+\eta_{\mathrm{bp}} \varepsilon_{\mathrm{Pc}}+\eta_{\mathrm{bc}}\right)+S_{\mathrm{P}}\left(\eta_{\mathrm{pb}} \varepsilon_{\mathrm{bc}}+\eta_{\mathrm{pp}} \varepsilon_{\mathrm{pc}}+\eta_{\mathrm{pc}}\right)
\end{aligned}
$$

The expression for $\eta_{c m}$ is:

$$
\left[\frac{\mathrm{dq}_{\mathrm{c}}}{\mathrm{dP}_{\mathrm{m}}} \frac{\mathrm{P}_{\mathrm{m}}}{\mathrm{q}_{\mathrm{c}}}\right]=\left[\frac{\mathrm{dq}_{\mathrm{c}}}{\mathrm{dP}_{\mathrm{c}}} \frac{\mathrm{P}_{\mathrm{c}}}{\mathrm{q}_{\mathrm{c}}}\right]\left[\frac{\mathrm{dP}_{\mathrm{c}}}{\mathrm{dP}_{\mathrm{m}}} \frac{\mathrm{P}_{\mathrm{m}}}{\mathrm{P}_{\mathrm{c}}}\right]=\varepsilon_{\mathrm{cm}} \eta_{\mathrm{cc}}
$$


$\mathrm{S}_{\mathrm{b}}=\frac{\mathrm{q}_{\mathrm{b}}}{\mathrm{q}_{\mathrm{m}}}$ is the share of beef quantity in the composite good, $\mathrm{S}_{\mathrm{p}}=\frac{\mathrm{q}_{\mathrm{p}}}{\mathrm{q}_{\mathrm{m}}}$ is the share of pork quantity in the total composite good, $\mathrm{P}_{\mathrm{m}}=\mathrm{S}_{\mathrm{b}} \mathrm{P}_{\mathrm{b}}+\mathrm{S}_{\mathrm{p}} \mathrm{P}_{\mathrm{p}}$ is the price of the composite good, $\varepsilon_{\mathrm{im}}=\left[\frac{\mathrm{dP}_{\mathrm{i}}}{\mathrm{dP}_{\mathrm{m}}} \frac{\mathrm{P}_{\mathrm{m}}}{\mathrm{P}_{\mathrm{i}}}\right]$ is the price elasticity of the $\mathrm{i}^{\text {th }}$ meat with respect to the price of the composite good and $\eta_{i j}=\left[\frac{\mathrm{dq}_{\mathrm{i}}}{\mathrm{dP}_{\mathrm{j}}} \frac{\mathrm{P}_{\mathrm{j}}}{\mathrm{q}_{\mathrm{i}}}\right]$ for $\mathrm{j}=\mathrm{c}, \mathrm{p}, \mathrm{b}$, and $\mathrm{i}=\mathrm{c}, \mathrm{p}, \mathrm{b}$ is the price elasticity of demand for three meats with respect to the price of beef and pork, respectively.

To obtain numerical measures for (24), (25), and (26), we obtained the cross and own elasticities of pork, chicken, and beef from Huang and Haidacher (1989) and estimated our own elasticities of price of beef and pork with respect to price of chicken $\left(\varepsilon_{\mathrm{bc}}\right.$ and $\varepsilon_{\mathrm{Pc}}$ ) by regressing the logarithmic price of beef on that of chicken and pork, respectively. Similarly, we estimated the elasticities of price of beef, pork, and chicken with respect to the price of the composite good ( $\varepsilon_{\mathrm{bm}}, \varepsilon_{\mathrm{pm}}$ and $\varepsilon_{\mathrm{cm}}$ ) by regressing the logarithmic price of beef, pork, and chicken on that of the composite good, respectively.

Substitution of the numerical estimates of (24), (25) and (26) into 22 yields a $\sigma=0.37$. Based on the results summarized in Proposition 2, consumers and farmers are better after the merger if the cost savings exceed 0.37 percent. Based on Proposition 4, the value of $\sigma$ implies that the merger improves social welfare if the cost savings are larger than 0.15 percent. The threshold values of 0.37 and 0.15 should be considered as crude approximations, at best, since $\sigma$ is not independent of the values of the price elasticities and the parameter values and functional forms of consumer demand, farm supply, and processing cost relationships used to formulate the stylized model.

However, as long as beef, pork, and chicken own- and cross-price elasticity estimates in the literature do not radically deviate from one another, and we do not expect properly estimated ones to do so, the value of $\sigma$ should not deviate radically from 0.37 either. In that case, we can expect that a mega merger, like Tyson-IBP, to generate that much cost savings, thereby making consumers and farmers better off as explained in Proposition 2. We are not so confident about the condition for social welfare improvement in Proposition 4 because, unlike the result in Proposition 2, the result in Proposition 4 is not insensitive to the structure of the stylized model and the assumed parameter values used therein.

\section{SUMMARY AND CONCLUSION}

This paper has examined the implications of a merger between firms with undifferentiated demand-related products. This type of a merger results in a multiproduct firm where optimal output is conditioned not only on the firm's multiproduct cost structure, but also on both own- and cross-market responses to variations in its own outputs and prices, and on the own- and cross-price elasticities of demand of each product. Overall, the effects of this type of a merger hinge on the magnitude of the substitutability effect relative to that of the cost effect. Thus, analytical results reveal that if the merger generates cost savings through economies of scope that are larger than the magnitude of the substitutability effect, then the merger is welfare-improving and hence socially desirable. Apart from the non-merged firms, which are worse off, all the remaining participating parties (i.e., farmers, consumers and the merged entity) are better off. On the other hand, if the size of the substitutability effect is larger than that of the cost effect or in the presence of diseconomies of scope, the merger reduces total economic surplus and hence is socially undesirable.

Results from the application of the model to Tyson-IBP merger reveal that as long as the cost savings are larger than 0.15 percent, the Tyson-IBP merger improves consumer and farmer welfare. Although we do not know whether or not the actual cost savings of the merger are larger or smaller than the 0.15 percent, it would seem implausible that Tyson would have opted for a mega merger that generates less than 1 percent in cost savings! The conclusion is that the merger may not be as harmful as some policy makers and livestock producers thought. 


\section{AUTHOR INFORMATION}

David Bouras is Associate Professor of Economics at Lincoln University, USA. He received his PhD from Nebraska University at Lincoln. His research interests include applied optimization, business forecasting and New Empirical Industrial Organization. E-mail: bourasd@ lincolnu.edu (Corresponding author)

Azzeddine Azzam is Professor of Agricultural Economics at the University of Nebraska-Lincoln, USA. He received his PhD from Nebraska University at Lincoln. His research interests include applied microeconomics and empirical industrial organization. E-mail: aazzam1@unl.edu

\section{REFERENCES}

1. Deneckere, R., and C. Davidson. (1985). Incentives to Form Coalitions with Bertrand Competition. Rand Journal of Economics 16: 473-86.

2. Farrell, J., and C. Shapiro. (1990). Horizontal Mergers: An Equilibrium Analysis. American Economic Review 80: 107-126.

3. Huang, K.S., and R.D. Haidacher. (1989). An Assessment of Price and Income Effects of Changes in Meat Consumption. In The Economics of Meat Demand (Reuben C. Buse, Editor). Proceedings of the Conference on the Economics of Meat Demand, October 20-21, 1986, Charleston, South Carolina.

4. McInnis, D. (2001). Teaming Up. Beef Magazine, May 1. Available at: http://beefmag.com/mag/beef teaming/index.html

5. Mcelroy, F. (1993). The Effects of Mergers in Markets for Differentiated Products. Review of Industrial Organization 8: 69-81.

6. Perry, M., and R. Porter. (1985). Oligopoly and the Incentive for Horizontal Merger. American Economic Review 75: 219-227.

7. Press Release. (2001). Grassley Takes Action for Family Farmers as Tyson-IBP Merger Talks Renew. Available at: http://grassley.senate.gov/releases/2001/p01r6-21.htm

8. Salant, S., S. Switzer, and J. Reynolds. (1983). Losses from Horizontal Mergers: the Effects of an Exogenous Change in Industry Structure on Cournot-Nash Equilibria. Quarterly Journal of Economics 98 : 185-99.

9. Shaked, A., and J. Sutton. (1990). Multiproduct Firms and Market Structure. Rand Journal of Economics 21: 45-62.

10. Symeonidis, G. (2002). Cartel Stability with Multiproduct Firms. International Journal of Industrial Organization 20: 339-352.

11. Vannoni, D. (2004). Causes and Effects of Multimarket Activity from Theory to Empirical Analysis. Managerial and Decision Economics 25: 163-174.

12. Ward C., and S. and Meyers. (2001). Competition Issues Associated with the IBP Acquisition. Mimeo. 


\section{APPENDIX A}

To establish the restriction $s \in(\infty-, \sigma+3]$, we note that:

$\mathrm{q}_{1}^{1}=\mathrm{q}_{2}^{2}=\frac{3}{2\left(12 \sigma+\sigma^{2}-\mathrm{s}(6+\sigma)+27\right)}$

$\mathrm{q}_{1}^{2}=\mathrm{q}_{2}^{1}=\frac{\sigma-\mathrm{s}+3}{2\left(12 \sigma+\sigma^{2}-\mathrm{s}(6+\sigma)+27\right)}$

For $\mathrm{q}_{1}^{2}$ and $\mathrm{q}_{2}^{1}$ to be positive, $s$ should be restricted to:

$\mathrm{s} \in(\infty-, \sigma+3] \cup\left[(\sigma+3)+\frac{9+3 \sigma}{6+\sigma},+\infty\right)$

For $\mathrm{q}_{1}^{1}$ and $\mathrm{q}_{2}^{2}$ to be positive, $s$ should be restricted to:

$\mathrm{s} \in\left(\infty-,(\sigma+3)+\frac{9+3 \sigma}{6+\sigma}\right)$

It follows from (A.1) and (A.2) that $s$ should be restricted to $\mathrm{s} \in(\infty-, \sigma+3]$ to ensure that both quantities are positive. 


\section{APPENDIX B}

B.1 Given the restriction $s \in(\infty-, \sigma+3]$ to ensure positive quantities, it follows that $\left(12 \sigma+\sigma^{2}-s(6+\sigma)+27\right)>0$. Multiplying through the latter inequality by $(2 \sigma+9)$ yields $\left(12 \sigma+\sigma^{2}-\mathrm{s}(6+\sigma)+27\right)(2 \sigma+9)>0$.

B.2 For $s>\sigma$ and $\mathrm{s} \in(\infty-, \sigma+3]$, it follows that $\sigma \leq \mathrm{s} \leq 3+\sigma$. Multiplying both side of the latter inequality by $-(21+4 \sigma)$ throughout gives:

$-63-33 \sigma-4 \sigma^{2}<-s(21+4 \sigma) \leq-21 \sigma-4 \sigma^{2}$

Adding $\left(45 \sigma+4 \sigma^{2}+108\right)$ on both sides of the B.2.1 and rearranging gives:

$45+12 \sigma<\left[\left(45 \sigma+4 \sigma^{2}+108\right)-\mathrm{s}(21+4 \sigma)\right] \leq 108+44 \sigma$

Since $\sigma>0$, therefore, $\left[\left(45 \sigma+4 \sigma^{2}+108\right)-\mathrm{s}(21+4 \sigma)\right]>0$.

B.3 To show that $\Phi>0$, rewrite it as:

$\Phi=\left[(\mathrm{s}-\sigma)\left(162+108 \sigma+24 \sigma^{2}+2 \sigma^{3}\right)+\mathrm{s}\left(243+180 \sigma+36 \sigma^{2}+2 \sigma^{3}-\mathrm{s}\left(24 \sigma+2 \sigma^{2}+72\right)\right)\right]$.

The first term is positive as long as $\mathrm{s}>\sigma$. To sign the above formula, it suffices to sign the second term. For $s>\sigma$ and $\mathrm{s} \in(\infty-, \sigma+3]$, it follows that $\sigma \leq \mathrm{s} \leq 3+\sigma .-\left(24 \sigma+2 \sigma^{2}+72\right)$

$-216-144 \sigma-30 \sigma^{2}-2 \sigma^{3} \leq-\mathrm{s}\left(24 \sigma+2 \sigma^{2}+72\right) \leq-72 \sigma-24 \sigma^{2}-2 \sigma^{3}$

Adding $\left(243+180 \sigma+36 \sigma^{2}+2 \sigma^{3}\right)$ on both sides of (1.3.1) results in:

$27+36 \sigma+6 \sigma^{2} \leq\left(243+180 \sigma+36 \sigma^{2}+2 \sigma^{3}-\mathrm{s}\left(24 \sigma+2 \sigma^{2}+72\right)\right)$

$\leq 243+108 \sigma+12 \sigma^{2}$

Since $\sigma>0$, therefore, $\left(243+180 \sigma+36 \sigma^{2}+2 \sigma^{3}-\mathrm{s}\left(24 \sigma+2 \sigma^{2}+72\right)\right)>0$. The result implies that $\left(243+180 \sigma+36 \sigma^{2}+2 \sigma^{3}-s\left(24 \sigma+2 \sigma^{2}+72\right)\right)>0$ is always positive provided that $\mathrm{s}>\sigma$. 
B.4 The first term in the numerator, $(3 \sigma+9-\mathrm{s})$, is always positive, the reason being $\mathrm{s} \in(\infty-, \sigma+3]$ or $\infty-\leq \mathrm{s} \leq 3+\sigma$. Multiplying by $(-1)$ on both sides of the latter inequality yields $-(3+\sigma) \leq-\mathrm{s} \leq+\infty$. Adding $(3 \sigma+9)$ throughout yields:

$2 \sigma+6 \leq 3 \sigma+9-\mathrm{s} \leq+\infty$. Therefore, the sign of $\triangle T E S$ depends on that of $\left(15 \mathrm{~s}-6 \sigma+3 \mathrm{~s} \sigma-\sigma^{2}\right)$. The latter term is positive when $s>\frac{\sigma(\sigma+6)}{3(\sigma+5)}$. 


\section{NOTES}

